\title{
Alternative splicing in the neural cell adhesion molecule pre-mRNA: regulation of exon 18 skipping depends on the $5^{\prime}$-splice site
}

\author{
Roland Tacke ${ }^{1}$ and Christo Goridis \\ Centre d'Immunologie, Institut National de la Santé et de la Recherche Médicale, Centre National de la Recherche \\ Scientifique de Marseille-Luminy, F-13288 Marseille Cédex 9, France
}

\begin{abstract}
Two isoforms of the neural cell adhesion molecule (NCAM), termed NCAM-180 and NCAM-140, derive from a single gene via inclusion or exclusion of the penultimate exon 18 (E18). This alternative splicing event is tissue-specific and regulated during differentiation. To explore its structural basis, we have analyzed the pattern of spliced mRNA generated from transiently transfected minigenes in N2a neuroblastoma cells, which up-regulate E18 usage during differentiation. We show that a minigene construct containing this exon and portions of the adjacent introns and exons faithfully reproduces the differentiation state-dependent alternative splicing of the endogenous pre-mRNA. By systematic deletion and replacement analysis, we scanned the minigene for the presence of functionally important cis-elements. We identified two sequences that affected differentiation state-dependent regulation. One, the central part of E18, does not seem to contain a specific cis-element essential for proper splice site choice, because extending the deletion restored correctly regulated expression of the splicing products. In contrast, the 5 '-splice site is an important element for regulation. Replacing it with a corresponding sequence from the $\alpha$-globin gene resulted in constitutive use of the optional exon. When placed in the a-globin gene it did not promote alternative splicing. Instead, we observed a strongly decreased efficiency of splicing of the downstream intron in undifferentiated cells. This block of splicing was partially relieved after differentiation. The results are consistent with a model in which skipping of E18 is controlled in part at the associated 5 '-splice site by trans-acting factors that undergo quantitative or qualitative changes during differentiation of N2a cells.
\end{abstract}

[Key Words: Pre-mRNA processing; alternative splicing; NCAM; 5'-splice site]

Received December 21, 1991; revised version accepted May 30, 1991.

Alternative splicing of mRNA precursors plays a fundamental role in the regulation of eukaryotic gene expression. In many cases, it provides a mechanism to produce structurally related but distinct proteins from a single gene. Numerous examples illustrate that alternative splicing and, thus, the expression of the resulting protein isoforms, can be regulated in a developmental or tissuespecific fashion (for review, see Smith et al. 1989a); but little detailed knowledge has emerged regarding the mechanisms of this regulation. A number of different sequences in mRNA precursors have been shown to influence alternative splice site selection. Perhaps not surprisingly, the recognition elements essential for constitutive splicing (for review, see Padgett et al. 1986) feature prominently among them: the region of the $5^{\prime}$-splice site (Fu and Manley 1987; Zhuang et al. 1987; Nasim et al. 1990; Siebel and Rio 1990), the $3^{\prime}$-splice site with its

${ }^{1}$ Corresponding author. associated polypyrimidine tract (Fu et al. 1988; Emeson et al. 1989; Sosnowski et al. 1989; Helfman et al. 1990|, and branchpoint sequence or location /Gattoni et al. 1988; Noble et al. 1988; Reed and Maniatis 1988; Helfman and Ricci 1989; Smith and Nadal-Ginard 1989; Goux-Pelletan et al. 1990). Other sequences in the premRNA may also be involved in alternative splice site selection and may be located within introns (Goux-Pelletan et al. 1990; Helfman et al. 1990) or exons (Reed and Maniatis 1986; Mardon et al. 1987; Streuli and Saito, 1989; Libri et al. 1990; Nagoshi and Baker 1990).

How these sequences function is still poorly understood. Trans-acting factors must be involved in splice site selection where alternative splicing of the same primary transcript has been shown to be cell type- or developmental stage-specific. Recently, some progress has been made toward characterizing candidate factors in several systems. These include the products of the Drosophila sex-determining genes transformer-2 (Am- 
rein et al. 1988) and Sex-lethal (Sosnowski et al. 1989; Inoue et al. 1990), which share sequence similarity with known RNA-binding proteins (for review, see Bandziulis et al. 1989|, and a 97-kD RNA-binding protein that may be involved in somatic repression of Drosophila P-element splicing (Siebel and Rio 1990). In vertebrates, the existence of developmental stage- and tissue-specific small nuclear ribonucleoprotein (snRNP) components has been documented (for review, see Mattaj and Hamm 1989|, but whether or not they participate in splicing control has remained unclear. Two possibly related factors, ASF (Ge and Manley 1990) and SF2 (Krainer et al. 1990a, bl, have been identified, which are involved in controlling 5'-splice site choice; however, their precise mechanism of action has not been elucidated. That is not to say that each sequence element found to play a role in differential pre-mRNA processing is involved in specific factor binding. Some of these elements could also contribute to the formation of RNA secondary structure, thus determining the accessibility of splice sites (Solnick 1985; Eperon et al. 1988; Libri et al. 1990).

We have been characterizing the alternative splicing of the mouse neural cell adhesion molecule (NCAM) premRNA. The large $(>80 \mathrm{~kb})$ gene produces a single premRNA (Goridis et al. 1989; Hirsch et al. 1990) from which multiple protein isoforms arise by a combination of alternative splicing and use of different poly $(\mathrm{A})$ addition signals (Barbas et al. 1988; Santoni et al. 1989). The intron-exon organization seems to be conserved between mouse and chicken (Owens et al. 1987; Barbas et al. 1988; Goridis et al. 1989). As a general or primary cell-cell adhesion molecule (Edelman 1988; Rutishauser and Jessell 1988), NCAM is believed to play a critical role in specifying cell patterning and movement during early embryogenesis, but it has also been implicated in morphogenetic events in later development, including axon bundling (Landmesser et al. 1988), neuroblast migration (Silver and Rutishauser 1984), and myogenesis (Dickson et al. 1990). Two classes of NCAM proteins, NCAM-140 and NCAM-180, differ by the variable inclusion of an additional intracellularly located domain of 266 residues (Cunningham et al. 1987; Barthels et al. 1988). In contrast to NCAM-140, which lacks the extra domain, NCAM-180 accumulates at sites of cell-cell contact, is less mobile in the plane of the membrane, and interacts with the cytoskeleton (Pollerberg et al. 1986, 1987). The additional domain is encoded by a single, cassette-type exon, the penultimate exon of the gene, exon 18 in the terminology of Owens et al. (1987). In this study we present a molecular analysis of the alternative splicing events that lead to either omission or incorporation of this exon. As a model system, we used N2a neuroblastoma cells in which this process is subject to differentiation state-dependent regulation: Proliferating, undifferentiated cells express mainly the exon 18 (E18)lacking, differentiated cells mainly the E18-containing forms. We present evidence suggesting that the 5 '-splice site of the optional exon is a key regulatory element in the differentiation state-specific control of alternative splicing.

\section{Results}

Alternative splicing in the $3^{\prime}$ part of the NCAM gene generates two different mRNAs through the optional use of E18. Inclusion of the $800-b p$ exon results in a transcript of $6.9 \mathrm{~kb}$ (coding for NCAM-180), whereas its exclusion from the mature transcript leads to synthesis of a 6.1-kb mRNA /coding for NCAM-140) (Cunningham et al. 1987; Barbas et al. 1988). As shown previously, undifferentiated, proliferating N2a neuroblastoma cells produce mainly NCAM-140, whereas NCAM-180 becomes predominant after differentiation induced by dimethylsulfoxide (DMSO) or laminin (Pollerberg et al. 1986). Similar changes in the relative proportions of the corresponding mRNAs occur during DMSO-induced differentiation of N2a cells (Fig. 1), suggesting that the cells regulate splicing of E18 depending on their state of differentiation. We relied on a transient transfection assay to investigate the structural basis for the differentiation state-dependent switch in NCAM transcript pattern in N2a cells. First, we established that all cis-information necessary for correct cell type- and stage-specific expression of the transcripts containing or lacking E18 is contained within a $6.5-\mathrm{kb}$ gene fragment and that this expression is regulated at the level of pre-mRNA splicing. Modifications were then introduced into this fragment to define the sequence requirements for regulation.

\section{A 6.5-kb gene segment containing E18 reproduces cell type-and differentiation state-specific expression of native $m R N A s$}

The initial construct that we used ( $\mathrm{pNC16-19)}$ is depicted in Figure $2 \mathrm{~A}$ and contains, besides the alternatively spliced E18 itself, exon 17 (E17), part of exon 16 (E16) fused to the cytomegalovirus (CMV) promoter, most of exon 19 (E19), and all intervening sequences. A polyadenylation signal is provided by SV40 sequences.

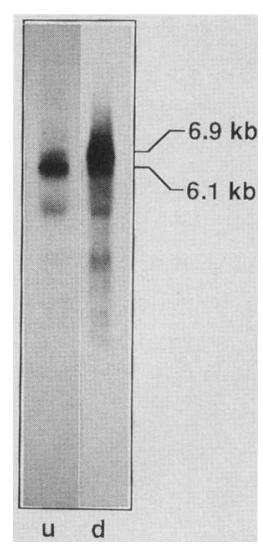

Figure 1. Northern blot analysis of the NCAM mRNA expression pattern in N2a cells that were undifferentiated $(\mathrm{u})$ or differentiated (d) with DMSO. The migration of the two main transcripts containing $(6.9 \mathrm{~kb})$ or lacking $(6.1 \mathrm{~kb}) \mathrm{E} 18$ is indicated. Small amounts of the shorter NCAM transcripts of 4.7 and 2.7 $\mathrm{kb}$ are also expressed in $\mathrm{N} 2 \mathrm{a}$ cells. 
Figure 2. RNase protection analysis of endogenous and exogenous NCAM transcripts resulting from alternative splicing of E18 in various cell lines. $(A)$ Representation of the terminal exons of the NCAM gene. The sequences present in the minigene construct (pNC16-19) are indicated by the heavy lines, and those of the alternatively spliced E18 are indicated by hatching. Restriction sites indicated are StuI (St), HpaI (Hp), BglI (Bg) PstI (Ps), KpnI $(\mathrm{Kp})$, and $\mathrm{BamHI}(\mathrm{Ba})$. The two probes used for RNase protection experiments are presented below. $(B, C)$ RNase protection analysis of RNA from undifferentiated $|u|$ and differentiated (d) mouse N2a cells, mouse L cells, and human HeLa cells. Fragments of 454 and 302 nucleotides result from protection of the $5^{\prime}$ probe by endogenous +E18 and -E18 transcripts, respectively, in N2a cells transfected with a carrier plasmid $(B)$. Expression from the minigene gives rise to protected fragments of $336(+\mathrm{E} 18)$ and 184 nucleotides (-E18). Sizes of the protected bands are indicated. As in all other figures, lanes sharing the same label are derived from transfections performed in duplicate. $(D)$ Relative proportions (in \%) of endogenous (end) and exogenous (exo) E18-containing $(+\mid$ and E18-lacking $(-)$ transcripts expressed in undifferentiated $(u)$ and differentiated $(d)$ N2a cells, in $L(L)$ and $\mathrm{HeLa}(\mathrm{H})$ cells. Endogenous expression of the NCAM gene was undetectable (nd) in L cells and could not be determined in human HeLa cells by RNase protection with the mouse NCAM probe. The bands representing the endogenous mRNAs in $C$ only become visible after longer exposure, because the minigene-derived transcripts are present in $>10$-fold excess.

We transfected this minigene into N2a cells and compared the patterns of endogenous and minigene-derived transcripts in undifferentiated and differentiated cells by RNase protection experiments, using a probe $\left(5^{\prime}\right.$ probe; see Fig. 2A) that discriminates among the four RNAs that are expected to be present: transcripts that contain E18 and those that do not, derived from either the native or the abridged gene. Two fragments of 454 and $302 \mathrm{nu}-$ cleotides, as expected for proper protection of the probe by the endogenous NCAM mRNAs of 6.9 and $6.1 \mathrm{~kb}$, respectively, were revealed in $\mathrm{N} 2 \mathrm{a}$ cells transfected with carrier plasmid only (Fig. 2B). N2a cells transfected with the minigene produced two transcripts that gave rise to protected bands of 336 and 184 nucleotides representing the transcripts with and without E18, respectively, derived from the transfected construct (Fig. 2C). Bands of 454 and 302 nucleotides corresponding to the endogenous mRNAs of the transfected cells were seen after longer exposure of the film (data not shown).

Quantification of the autoradiographic signals (Fig. 2D) showed that in undifferentiated cells, $\sim 30 \%$ of the endogenous transcripts contained the optional exon, whereas $\sim 70 \%$ lacked it. This ratio was approximately reversed after differentiation. The corresponding figures for the minigene-derived RNAs in this experiment were $28 \%$ E18-containing and $72 \%$ E18-lacking transcripts in undifferentiated cells and $63 \%$ and $37 \%$, respectively, in differentiated cells. Hence, the minigene faithfully reproduced regulated alternative splicing of E18. The
pNC16-19-derived transcripts were also alternatively spliced by mouse $\mathrm{L}$ and human HeLa cells, which do not express the endogenous gene, but E18 was incorporated to a lesser extent $(\sim 15 \%)$ than in undifferentiated N2a cells (Fig. 2C,D).

\section{Differentiation state-dependent expression of E18-containing and E18-lacking transcripts is not regulated by selective $m R N A$ transport or degradation}

Our results so far demonstrate that the pNC16-19 minigene contains all of the cis-information required for correct cell type- and stage-specific expression of its transcripts. However, effects resulting from regulation of alternative splicing are indistinguishable from those caused by post-splicing events. Differential transport or degradation of the splicing products could thus play a major role in generating the differentiation state-specific expression pattern. To test this possibility, two partial cDNAs (see Materials and methods) either containing or lacking the optional exon were cotransfected into N2a cells, and their relative expression was recorded in undifferentiated and differentiated cells by RNase protection. To avoid competition for factors that might be present in limiting amounts, plasmid concentrations were used that produced only moderate (about threefold) overexpression of the exogenous transcripts (Fig. 3). Untransfected N2a cells exhibited the differentiation statedependent differences usually observed in the expression 


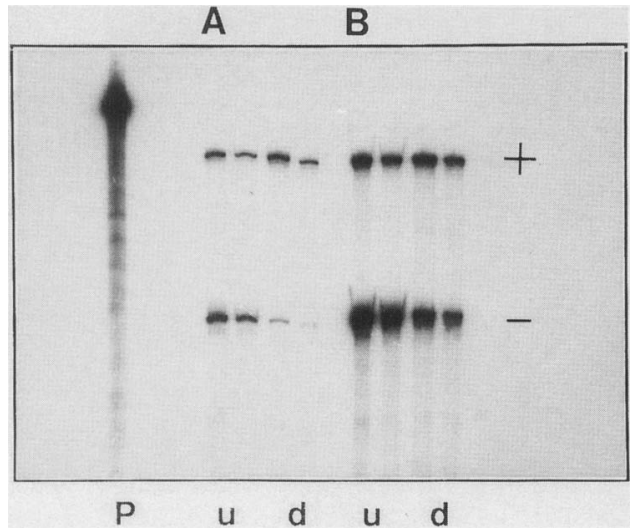

Figure 3. Expression pattern of partial cDNAs containing or lacking E18 in undifferentiated (u) and differentiated (d) N2a cells after cotransfection. Protection of the $5^{\prime}$ probe $(P)$ (see Fig. 2) by transcripts containing $(+\mid$ or lacking $|-|$ E18 is shown for untransfected $(A)$ or transfected $(B)$ cells. Note that the signals shown in $B$ result from protection of the probe by the sum of endogenous and exogenous transcripts.

pattern of the endogenous transcripts (Fig. 3A). Although our probe did not distinguish between exogenously and endogenously derived RNAs, it is apparent that after transfection the proportion of $+\mathrm{E} 18$ to $-\mathrm{E} 18$ transcripts had become rather similar in undifferentiated and differentiated cells (Fig. 3B). Quantification of the autoradiographic signals and correction for endogenous expression showed that in the transfected cells, the relative proportions of the two exogenous transcripts remained unchanged throughout differentiation (data not shown). These findings show that selective transport or degradation does not play an important role in controlling the level of NCAM mRNAs during N2a cell differentiation.

\section{Neighboring exons and most of the intervening sequences have little effect on the splicing pattern}

Splice site compatibility has been proposed as one mechanism for explaining regulated alternative splicing (Gallego and Nadal-Ginard 1990). This view implies that exons adjacent to E18 may play a dominant role in determining its utilization. To test this possibility, we constructed two variants of pNC16-19. In one, termed 16$18 / \mathrm{G} 3$, the third and last exon of the $\alpha$-globin gene, together with 104 nucleotides of upstream intron, replaced the truncated E19 and its immediate 5'-flanking sequences, including the putative branchpoint. In the second construct (16/18/19), E17 and much of its flanking introns were deleted (Fig. 4). The replacement of E19 and the adjacent intron sequences affected neither the ratio of + E18 to - E18 RNA nor the up-regulation of E18 usage during differentiation (Fig. 4A; Table 1). To analyze the transcripts generated from 16/18/19, a probe (termed 3' probe in Figs. 2A and 4) was used that had the potential to protect the $3^{\prime}$ part of E18 and the $5^{\prime}$ part of E19. Two bands were revealed that corresponded to the fully protected probe and to a 128-nucleotide fragment (134 nucleotides for the wild-type construct), representing the +E18 and -E18 RNAs, respectively (Fig. 4B). These bands include the signals derived from protection of the probe by the endogenous transcripts, but the transfection conditions that were used routinely ensured $\sim 10$-fold overexpression of the exogenously derived RNA. Construct $16 / 18 / 19$ yielded slightly higher proportions of E18-containing transcripts than did the basic minigene, but this was equally true for undifferentiated and differentiated cells and may reflect a higher efficiency in splicing of E16 to E18 than of E17 to E18. We conclude that neither of the flanking splice sites is essential for correct alternative splicing of E18.

These results already indicated that sequences $5^{\prime}$ to the BgIII site in the upstream intron, intervening sequence 17 (IVS17) (see Fig. 4), as well as the most 3' part of IVS18, were not required for regulated alternative splicing. To further test the role of the flanking introns, we deleted the region between the BgIII and SphI site 100 nucleotides $5^{\prime}$ of the E18 3'-splice site in IVS17 (con-

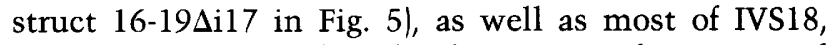
leaving only 184 nucleotides downstream from E18 and 112 nucleotides $5^{\prime}$ of E19 (construct 16-19دi18 in Fig. 6). The transcripts generated from both constructs were still alternatively spliced and exhibited differentiation statedependent regulation (Figs. 5 and 6; Table 1). In both cases, an increased incorporation of E18 was observed which, however, did not grossly affect the up-regulation during differentiation. Hence, shortening the flanking introns increases the efficiency of E18 selection in differentiated and undifferentiated cells, but the deleted sequences do not seem to contain cis-elements required for differentiation-dependent control.

\section{Deletions within E18 affect the splicing pattern}

The foregoing results indicated that potential cis-information necessary for regulated alternative splicing of E18 is confined to the optional exon itself and the immediately adjacent intron sequences. We thus proceeded to delete sequences within E18 using the centrally located StuI site as a starting point for bidirectional exonuclease digestion. Three nested deletions, termed $\Delta 1-$ $\Delta 3$, that removed 293,437 , and $564 \mathrm{bp}$, respectively, were generated (Fig. 7). The smallest deletion, $\Delta \mathrm{l}$, severely impaired the incorporation of $\mathrm{E} 18$. The relative amounts of $+\mathrm{E} 18$ transcripts generated from the mutant construct were already clearly depressed in undifferentiated cells, and the DMSO-induced increase in E18 usage was almost completely abolished (Fig. 7; Table 1). One interpretation of these results is that we destroyed or removed a cis-acting element required for the differentiation state-dependent regulation of alternative splicing. This explanation would imply that larger deletions, including the sequences deleted in $\Delta \mathrm{l}$, exert similar effects. On the contrary, the larger deletion $\Delta 2$ already gave an expression pattern closer to the normal situation, and deletion $\Delta 3$ resulted in enhanced use of the mutant as compared to the intact exon both in undiffer- 
Figure 4. Effect of the flanking exons on E18 utilization in $\mathrm{N} 2 \mathrm{a}$ cells. The constructs used for transfection are shown at top. $\alpha$-Globin sequences are represented by the solid box. Restriction sites AccI (A), BglII (B), SphI (Sp), StuI $(\mathrm{S}), \operatorname{PstI}(\mathrm{P})$, and $\mathrm{HpaI}(\mathrm{H})$ are indicated. $(A, B)$ RNase protection analysis of transfected undifferentiated $(\mathrm{u})$ and differentiated $(\mathrm{d})$ cells with $5^{\prime}(A)$ or $3^{\prime}(B)$ probes, respectively. In lane $M$, size markers were run alongside. Full protection of the $3^{\prime}$ probe minus linker sequences (171 nucleotides) represents splicing of E18 to E19. Partially protected fragments indicative of $\mathrm{E} 18$ exclusion are longer for the original (134 nucleotides) than for the mutant (128 nucleotides/ construct because of a 4-nucleotide sequence identity between the $5^{\prime}$ ends of E17 and E18. The fragments resulting from protection of the probe by endogenous NCAM transcripts are marked by asterisks $(*)$.

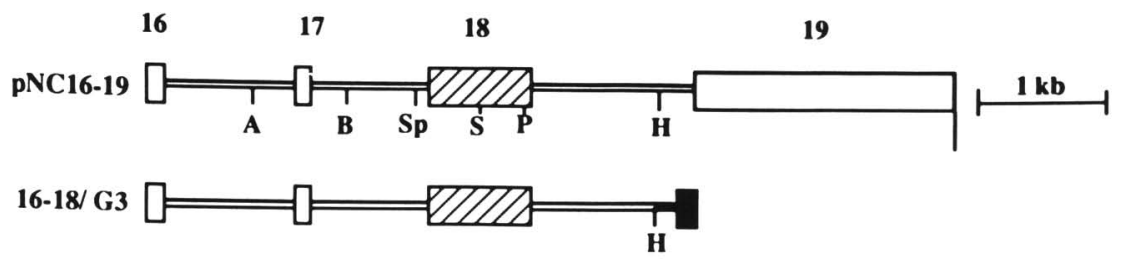

$16 / 18 / 19$

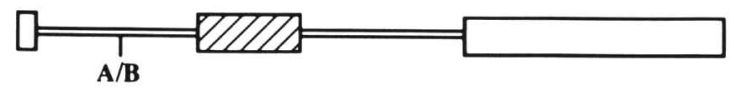

A

B

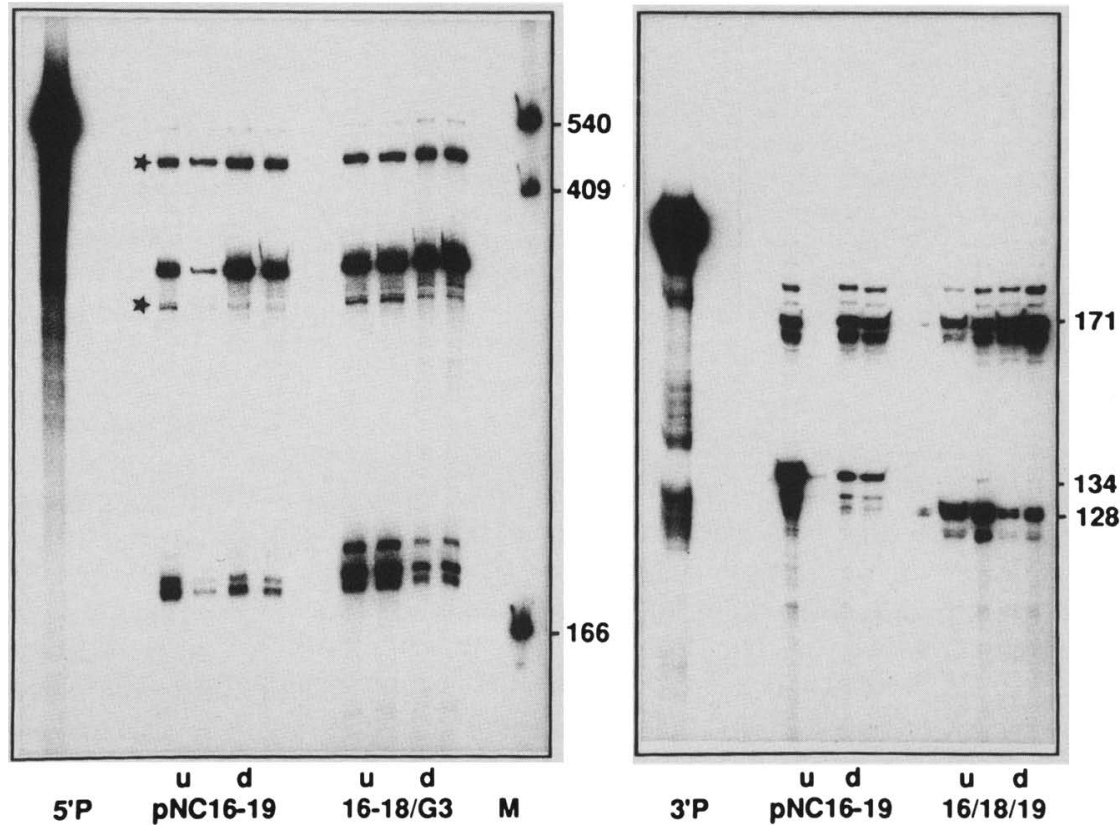

entiated and differentiated cells, thus restoring most of the DMSO-induced regulation (Fig. 7; Table 1). These results demonstrate that the integrity of E18 is of crucial importance for the correct expression of the two alternatively spliced transcripts. The effects are, however, difficult to reconcile with the action of a particular se-

Table 1. Synopsis of quantification of RNA-processing patterns generated by different constructs

\begin{tabular}{llllll}
\hline Construct & $\mathrm{u}$ & $\mathrm{d}$ & Construct & $\mathrm{u}$ & $\mathrm{d}$ \\
\hline pNC 16-19 & 29 & 69 & $16-19 \Delta \mathrm{i} 17$ & 51 & 85 \\
$16-18 / \mathrm{G} 3$ & 32 & 68 & $16-19 \Delta \mathrm{i} 18$ & 42 & 81 \\
$16 / 18 / 19$ & 44 & 77 & $16 / 17 / 18^{\mathrm{G} 2 \mathrm{a}} / 19$ & 23 & 39 \\
$\Delta 1$ & 16 & 19 & $16 / 17 / 18^{\mathrm{G} 2 \mathrm{~d}} / 19$ & 88 & 94 \\
$\Delta 2$ & 23 & 41 & $16 / 17 / 18^{\mathrm{G} 2 N 18 d} / 19$ & 26 & 60 \\
$\Delta 3$ & 48 & 77 & & & \\
\hline
\end{tabular}

The numbers represent the percent of total transcripts containing E18 in undifferentiated (u) N2a cells and after DMSO-induced differentiation (d). The values are the means of duplicate determinations from two to six independent experiments. Deviations from the mean value did not exceed $6 \%$. quence element within E18 and might be attributed to the altered overall structure of the pre-mRNA.

\section{Recognition of E18 as an optional exon depends on the $5^{\prime}$-splice site}

The results reported so far suggested that neither the flanking exons nor the intervening intron sequences (except perhaps those in the immediate proximity of the splice sites/ contain essential elements required for regulated splicing of E18. Deletions in E18 did affect splicing but failed to provide convincing evidence for the presence of specific sequences within the exon that might be the targets for regulatory factors. Therefore, we reasoned that such factors might act at the splice sites of the optional exon or in their immediate vicinity. We constructed two minigenes in which either the $3^{\prime}$ - or the $5^{\prime}$-splice site of E18 was replaced by the corresponding site from exon 2 of the $\alpha$-globin gene, together with short adjacent sequences.

In the first construct $\left(16 / 17 / 18^{\mathrm{G} 2 \mathrm{a}} / 19\right)$, we substituted a 119-bp sequence at the $5^{\prime}$ end of E18, which starts at the SphI site within IVS17 (thus including the putative 

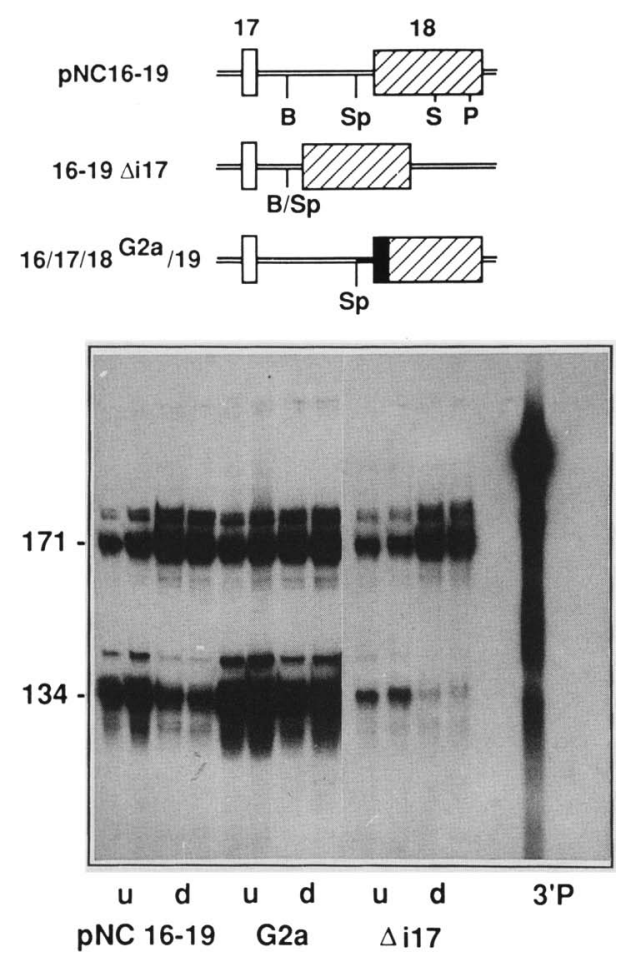

Figure 5. RNase protection analysis of RNA derived from 16$19 \Delta \mathrm{i} 17$ and $16 / 17 / 18^{\mathrm{G} 2 \mathrm{a}} / 19$ in undifferentiated $(\mathrm{u})$ and differentiated (d) N2a cells with the $3^{\prime}$ probe. The modifications introduced into the original minigene (pNC16-19) are schematically represented (top); only the relevant regions of the construct are shown. $\alpha$-Globin sequences containing the 3 '-splice site of the second exon (G2a) are marked by a heavy line (intron) and a solid box (exon). Sizes (in nucleotides) of the main protected fragments are indicated. The 171- and 134-nucleotide bands represent $+\mathrm{E} 18$ and $-\mathrm{E} 18$ transcripts, respectively. Minor bands of larger size are generated by staggered RNase cuts.

pyrimidine tract and branchpoint) and terminates $19 \mathrm{bp}$ past the $3^{\prime}$-splice site, by a fragment comprising $15 \mathrm{bp}$ of polylinker followed by 86 bp of IVS1 and 14 bp of exon 2 from the $\alpha$-globin gene. After transfection into N2a cells, the transcripts produced were analyzed with the $3^{\prime}$ probe (see Fig. 2A). The presence of two protected bands of the correct sizes indicated that alternative splicing still took place (Fig. 5). The ratio of +E18/-E18 RNAs was quite normal in undifferentiated cells, but the DMSO-induced up-regulation of E18 usage, though clearly detectable, was somewhat impaired (Table 1). We thus infer that alternative splicing per se does not rely on the E18 branchpoint and $3^{\prime}$-splice site but that differentiationdependent control is disturbed by the presence of the heterologous sequences.

Replacing the E18 5'-splice site yielded a very different result. In this construct $\left(16 / 17 / 18^{\mathrm{G} 2 \mathrm{~d}} / 19\right)$, the NCAM sequences comprising $34 \mathrm{bp}$ of the exon and $12 \mathrm{bp}$ of IVS18 were exchanged for a synthetic $\alpha$-globin exon $25^{\prime}$-splice site including $9 \mathrm{bp}$ of exon and $14 \mathrm{bp}$ of intron sequences together with $5 \mathrm{bp}$ from a ClaI-linker. N2a cells transfected with this construct expressed E18-containing transcripts almost exclusively, irrespective of their state of differentiation (Fig. 6A; Table 1). To ascertain that the mutant exon was now also used at a high level in other cell types, we expressed the construct in HeLa cells, which produce only low amounts of E18-containing transcripts from a transfected wild-type minigene (see Fig. 2D). Again, the vast majority of the transcripts generated contained the mutant exon (Fig. 6B). These data indicate that the 46-bp fragment that has been replaced in $16 / 17 / 18^{\mathrm{G} 2 \mathrm{~d}} / 19$ comprises an essential element for recognition of E18 as an alternative exon. To test whether the 5 '-splice site itself would be this element, the respective site in $16 / 17 / 18^{\mathrm{G} 2 \mathrm{~d}} / 19$ (AAG/GUGAGC) was mutated back to the E18 5'-splice site (CGA/ GUACGG). Expression of the resulting construct (16/17/ $18^{\mathrm{G} 2 \mathrm{~N} 18 \mathrm{~d} / 19)}$ was analyzed in undifferentiated and differentiated N2a cells by RNase protection with the $5^{\prime}$ probe. The splicing pattern was very similar to that produced by the wild-type minigene (Fig. 10A, below; Table 1). Hence, the genuine $5^{\prime}$-splice is essential to recognition of E18 as an alternative exon.

The E18 5'-splice site suppresses downstream splicing in a heterologous gene

The results presented in the preceding section raised the possibility that sequences including the E18 $5^{\prime}$-splice site would be able to induce exon skipping within a heterologous gene. To test this possibility, we grafted a fragment starting $35 \mathrm{bp} 5^{\prime}$ of and terminating $94 \mathrm{bp} 3^{\prime}$ of the E18 5'-splice site, together with sequences of a ClaI linker, at either end into the $\alpha$-globin gene in exchange for the 3 ' half of its second exon and $44 \mathrm{bp}$ of the adjacent intron (construct 2 in Fig. 8A). The mutant construct, as well as the wild-type globin gene (construct 1), was placed into the vector used for expression of the NCAM minigene. After transfection into N2a cells, the RNAprocessing pattern was analyzed by primer extension coupled to amplification by polymerase chain reaction (PCR). Expression of the wild-type gene yielded almost exclusively a PCR product of the size expected for the correctly spliced transcript (Fig. $8 \mathrm{~B}$ ). In contrast, the pattern generated from construct 2 contained a $430-\mathrm{bp}$ band in addition to the one representing joining of exon 1 (E1), the mutated exon 2 (E2'), and exon 3 (E3). It corresponded in size to a transcript that had retained the intron downstream of E2', a conclusion that was confirmed by sequence analysis of the isolated amplification product (data not shown). However, a band of $69 \mathrm{bp}$ that might indicate skipping of the mutant exon was not observed even when Southern blot analysis was used to enhance the sensitivity of detection. Because our results (see Fig. 4) indicated that NCAM E17 can be spliced to $\alpha$-globin E3, we replaced E1 and part of IVS1 in constructs 1 and 2 with a fragment of the NCAM gene that comprised E16 and E17 (constructs 3 and 4). Also, these constructs did not yield a PCR product that would indicate joining of E17 to E3 (Fig. 8B).

Inspection of the PCR analysis shown in Figure 8 al- 
Figure 6. RNase protection analysis of RNA derived from $16-19 \Delta \mathrm{i} 18$ and $16 / 17 /$ $18^{\mathrm{G} 2 \mathrm{~d}} / 19$ in undifferentiated $(\mathrm{u})$ and differentiated (d) N2a cells $(A)$ or from 16/17/ $18^{\mathrm{G} 2 \mathrm{~d}} / 19$ in HeLa cells $(B)$ with the $5^{\prime}$ probe. The variations with respect to the wildtype minigene ( $\mathrm{pNC16}-19$ ) are represented schematically (top). The $5^{\prime}$-splice site region of $\alpha$-globin E2 is marked by a solid box. The 336- and 184-nucleotide bands represent + E18 and - E18 transcripts, respectively.
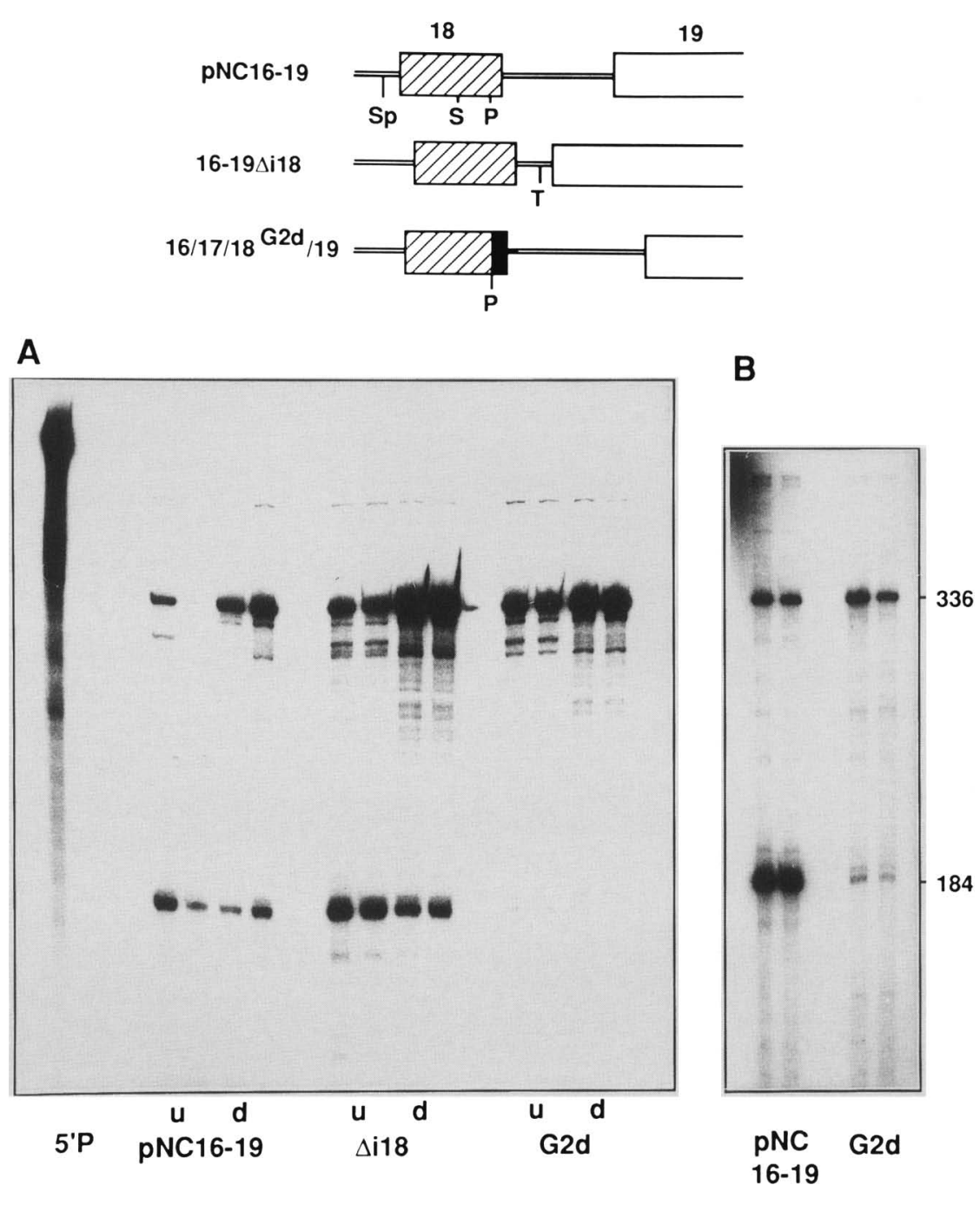

ready suggested differences in the extent of intron retention between undifferentiated and differentiated cells $/ \mathrm{cf}$. the two bands in lanes 2 and $4, u$ and d, in Fig. 8B/. To clarify this point, we performed quantitative RNase protection analysis using a probe derived from $\alpha$-globin exon 3 and part of IVS2. The results showed that $\sim 80 \%$ of the transcripts derived from construct 2 retained the second intron in undifferentiated cells as opposed to only $50 \%$ after differentiation (Fig. 9). Very similar values were obtained with the constructs in which exon 1 had been replaced by NCAM E16 and E17 (Fig. 9).

Finally, to address the question as to whether the E18 5 '-splice site itself would be sufficient to induce intron retention within the $\alpha$-globin gene, we mutated the E2 $5^{\prime}$-splice site (AAG/GUGAGC) to the E18 $5^{\prime}$-splice site (CGA/GUACGG) in this gene (construct $\mathrm{pGl} / 2^{\mathrm{N} 18 \mathrm{~d}} / 3$ ). Analysis of the transcripts by PCR amplification (Fig. $10 B$ ) and RNase protection (not shown) yielded results virtually identical to the ones (Figs. 8 and 9) obtained with construct 2 of Figure 8: Retention of the second intron was observed and was relatively more pronounced in undifferentiated than in differentiated cells. We thus conclude that the E18 $5^{\prime}$-splice site is involved in the control of its own utilization during N2a cell differentiation.

\section{Discussion}

Alternative utilization of the penultimate E18 of the NCAM gene is the mechanism by which N2a neuroblastoma cells undergoing morphological differentiation switch from a predominant expression of NCAM-140 to a predominant expression of NCAM-180, which contains an additional cytoplasmic domain. In this study we investigated the structural basis for this regulation.

\section{Role of the E18 5'-splice site in regulating alternative} splicing

When a sequence of only 46 nucleotides encompassing the 5 '-splice site of E18 was replaced by a corresponding 

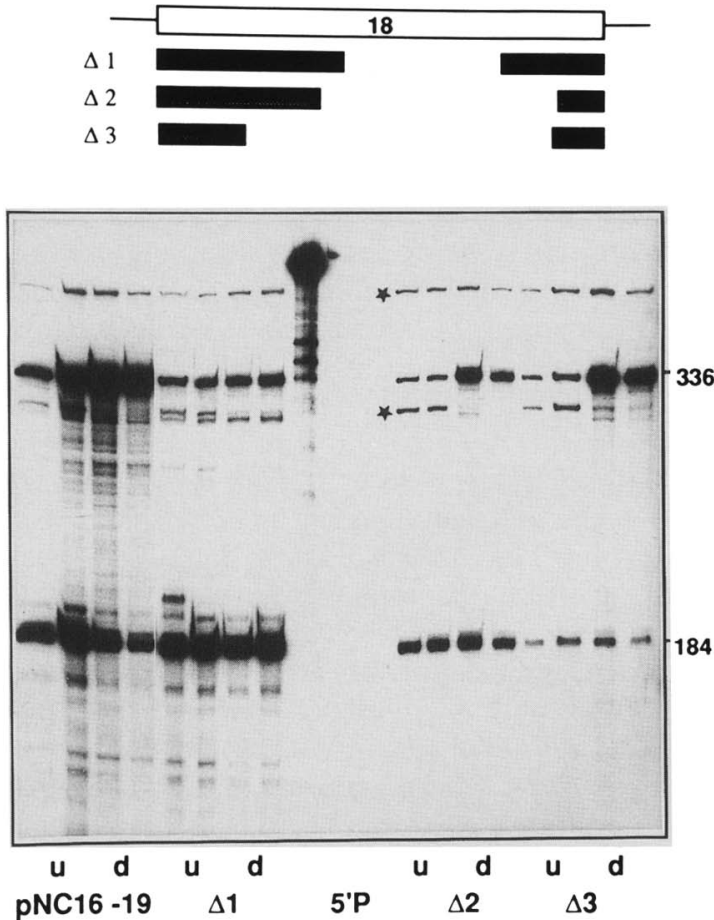

Figure 7. Effect of internal deletions $(\Delta 1-\Delta 3)$ within E18 (top) on the relative expression of exogenous transcripts in undifferentiated $(\mathrm{u})$ and differentiated (d) N2a cells. The $5^{\prime}$ probe was used for RNase protection analysis. Asterisks $\left({ }^{*}\right)$ indicate fragments due to protection by endogenous NCAM transcripts.

region from $\alpha$-globin E2 in the otherwise identical minigene, the alternative exon was almost constitutively used in both undifferentiated and differentiated N2a cells. This was true also for HeLa cells, which generate only low levels of E18-containing transcripts from the wild-type minigene. Mutating the $5^{\prime}$-splice site back to the original E18 $5^{\prime}$ '-splice site was sufficient to restore the wild-type splicing phenotype in N2a cells. Taken together, these findings unambiguously demonstrate that the genuine $5^{\prime}$-splice site is absolutely required for regulated alternative splicing of E18 while immediately adjacent sequences are dispensable. To determine whether sequences containing the E18 $5^{\prime}$-splice site would induce alternative splicing of a constitutive exon in another gene, we replaced a segment of the $\alpha$-globin gene centered around the E2 5 '-splice site by an NCAM fragment containing the E18 $5^{\prime}$-splice site plus adjacent intron sequences. Alternative splicing was not observed. Instead, this substitution severely inhibited the removal of the following intron. Most importantly, this block of splicing was partially relieved after differentiation. Virtually identical results were obtained when only the $9 \mathrm{bp}$ constituting the $5^{\prime}$-splice site of $\alpha$-globin E2 was exchanged for the corresponding site from E18. These findings demonstrate that the E18 $5^{\prime}$-splice site is subject to differentiation state-dependent regulation, which operates at the level of the splice site itself.

How may this regulation be accomplished? One pos-
A

1

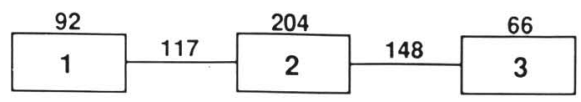

2

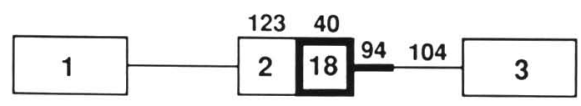

3

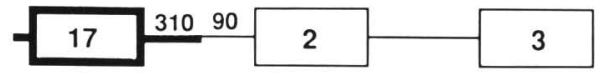

4

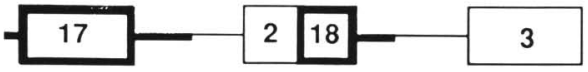

B
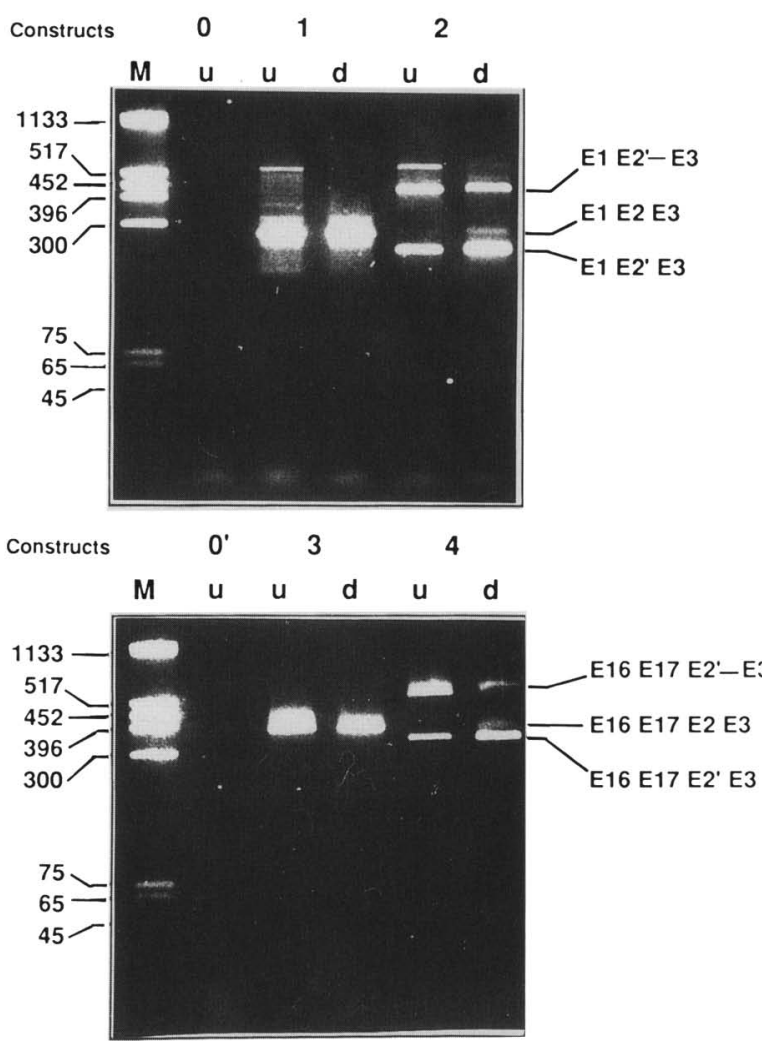

Figure 8. PCR analysis of the transcripts produced from $\alpha$-globin/NCAM chimeric constructs. $(A)$ Schematic diagram of the four minigenes (1-4) used for transfection. Exon and intron sequences derived from the NCAM gene are marked by heavy lines. The lengths of exon and intron fragments (in bp) are also indicated. Note that only the $5^{\prime}$ part of $\alpha$-globin E3 is present in the constructs. $(B)$ An ethidium bromide-stained agarose gel is shown. Amplified (17 cycles) products of reverse transcription (for primers used, see Materials and methods) of RNA from undifferentiated $(\mathrm{u})$ and differentiated (d) N2a cells transfected with the constructs represented in $A$ (lanes 1-4) or with carrier plasmid only (lanes $O$ and $O^{\prime}$ ). In lanes $M$, size markers were run alongside. The weak bands (lanes $1 u, 2 u$ ) represent either unspliced mRNA precursors or a contamination of the RNA preparation with minigene DNA. The splicing products of the different constructs are represented schematically at right. The dash represents the retained intron; (E2') the chimeric exon. 


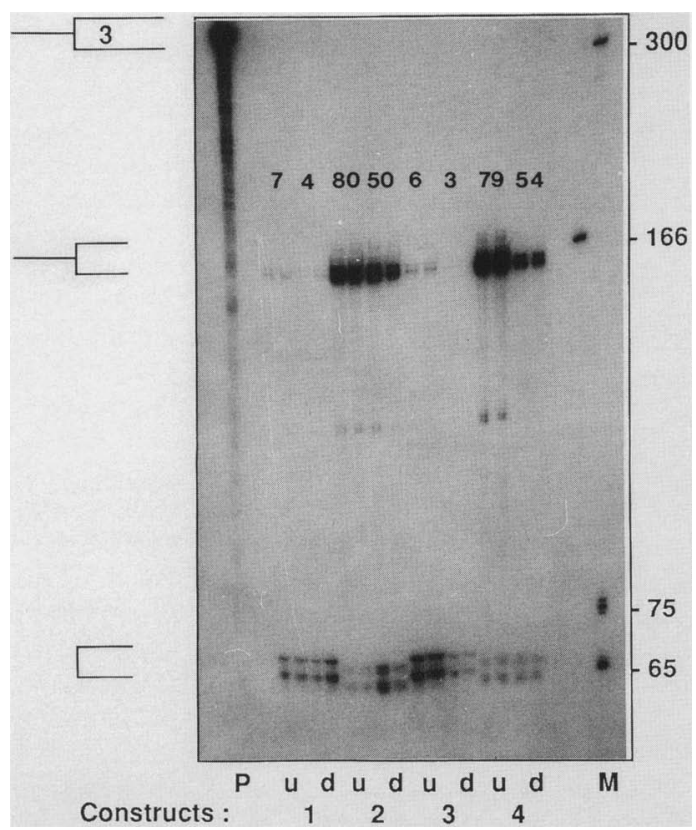

Figure 9. RNase protection analysis of the splicing products generated in undifferentiated $(\mathrm{u})$ and differentiated (d) N2a cells from the minigene constructs 1-4 represented in Fig. $8 \mathrm{~A}$. The probe (lane $P$ ) and the protected fragments are represented at left. Note that the probe contains an additional 3' 111 nucleotides of E3 as compared to the constructs. (lane $M$ ) Size markers were run alongside; their sizes are given in bp. The relative proportions (in \%) of the fragments due to protection by the intron-retaining transcripts are shown above the corresponding bands.

sibility is that the 5 '-splice site terminating E18 is intrinsically weak and its efficient use depends on a transacting factor present in higher concentrations in differentiated than in undifferentiated cells. The E18 $5^{\prime}$-splice sites of both the mouse (CGA/GUACGG) and the chicken (CGA/GUAUGG) (Owens et al. 1987) genes match the consensus sequence (MAG/GURAGU) in only 5 of 9 positions, in contrast to the $8 / 9$ match of the corresponding $\alpha$-globin exon 2 site. This raises the possibility that E18 skipping results primarily from poor binding of U1 snRNP to this weak splice site and that efficient binding requires the presence of a trans-acting factor. Such a model is supported by studies showing that the degree of homology with the consensus sequence determines the selection among competing $5^{\prime}$ splice sites (Eperon et al. 1986; Fu and Manley 1987; Zhuang et al. 1987; Lear et al. 1990) and by the work of Kuo et al. (1991), who demonstrated that weak binding of U1 snRNP to the 5'-splice site is responsible for exon skipping in the preprotachykinin pre-mRNA. Recently, two possibly related factors, termed ASF /Ge and Manley 1990) and SF2 (Krainer et al. 1990a), have been identified that promote use of and influence selection among competing 5 '-splice sites in a concentration-dependent manner. Furthermore, SF2 was found to be required for efficient splicing of several pre-mRNA substrates (Krainer et al. 1990b|. Regardless of whether or not ASF or SF2 will turn out to play a role in the regulation of E18 skipping, these studies lend support for the hypothesis that different concentrations of a splicing factor that promotes recognition of 5'-splice sites account for the cell type-specific variations in E18 usage.

In an alternative model, an inhibitory factor may suppress usage of the E18 5'-splice site. Such a mechanism has been proposed to explain splice site selection in a variety of genes (Emeson et al. 1989; Sosnowski et al. 1989; Zachar et al. 1987; Inoue et al. 1990; Siebel and Rio 1990). However, the data showing that E18 is preferentially skipped in the two cell lines tested that do not transcribe the endogenous gene may be taken to mean that a low level of E18 usage is the default pathway not requiring additional factors.

With our present data we cannot explain why the E18 5 '-splice site induces intron retention in the context of the $\alpha$-globin gene, a phenomenon that we did not observe with the wild-type or any of the mutant versions of the NCAM minigene where exon skipping occurs instead. The simplest interpretation would be that splicing of $\alpha$-globin E1 and E2 takes place so fast that it out-competes exon skipping, resulting in a buildup of partially spliced RNA. Further work is required to prove that splice site competition accounts for our failure to induce exon skipping in the $\alpha$-globin gene. In particular, it will be interesting to learn whether the order of intron removal is the same in the NCAM and the mutated $\alpha$ globin gene.

\section{Sequences located within E18 affect alternative splicing}

Striking effects of exon sequences on tissue-specific alternative RNA processing have been reported for fibronectin exon EDIIIA (Mardon et al. 1987) and for E4 and E6 of CD45 (Streuli and Saito 1989; Tsai et al. 1989). In the latter two studies, linker scanning mutations introduced into the optional exons resulted in their use in $T$ cells, which normally skip them. In our system, a deletion of the central part of E18 did not induce constitutive splicing but suppressed exon usage in undifferentiated cells and abolished differentiation-dependent regulation. Because extension of the deletion restored normal regulation, the effect cannot be explained by the removal of a specific cis-element that may be the target of a transacting factor. Hence, perturbation of RNA secondary structure may be involved affecting either splicing of the pre-mRNA or transport or stability of the mRNA containing the mutant exon. Further analysis is required to distinguish among these possibilities.

Role of flanking exon and intron sequences and of the $3^{\prime}$-splice site of E18

In contrast to the striking effects elicited by substitution of the $5^{\prime}$-splice site and by deletions within E18, a num- 
A

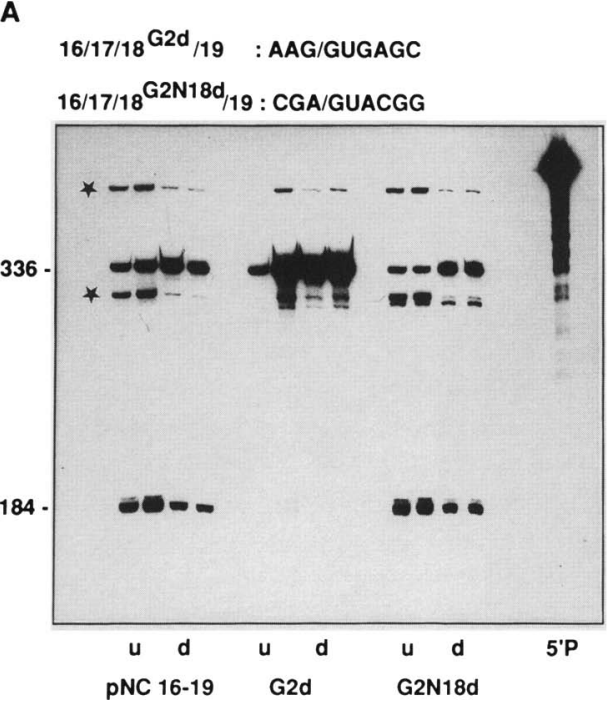

B

$\alpha$ - globin (Wt) : AAG/GUGAGC

$1 / 2^{\mathrm{N} 18 \mathrm{~d} / 3}$ : CGA/GUACGG

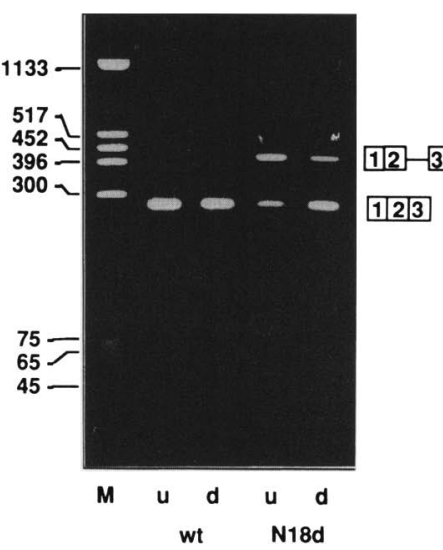

Figure 10. (A) Effect of the 5 '-splice site on E18 skipping in N2a cells. Constructs $16 / 17$ / $18 / \mathrm{G} 2 \mathrm{~d} / 19$ (represented schematically in Fig. $6 /$ and $16 / 17 / 18^{\mathrm{C} 2 \mathrm{~N} 18 \mathrm{~d}} / 19$ are identical except for the sequence of 9 nucleotides constituting the $5^{\prime}$-splice site of the mutant exon as indicated at top. Fragments of 336 and 184 nucleotides are due to protection of the 5' probe by + E18 and - E18 transcripts, respectively, derived from the different constructs in undifferentiated $(\mathrm{u})$ and differentiated (d) N2a cells. Bands marked with asterisks (*) indicate protection by the endogenous transcripts. $(B)$ Effect of the $5^{\prime}$-splice site on the splicing efficiency of the $\alpha$-globin IVS2 in undifferentiated (u) and differentiated (d) N2a cells. A PCR analysis of the transcripts derived from the transfected wild-type (wt) or a mutant (1) $2^{\mathrm{N} 18 \mathrm{~d}} / 3$ ) gene containing the E18 $5^{\prime}$-splice site is shown. The sequences of the different $5^{\prime}$ splice sites are shown at top. The upper band in lanes N18d $u$ and $d$ is indicative of intron retention. (Lane $M$ ) A size marker was run alongside. ber of other modifications affected splicing only slightly or not at all. We can thus exclude the splice sites of the neighboring exons as major determinants of splice site choice in our system. Because regulated alternative splicing was preserved when large parts of the flanking introns had been deleted, we can also discount the possibility that long-range sequence interactions leading to a special secondary structure play a decisive role. However, three mutant constructs exhibited a tendency for increased inclusion of E18, perhaps due to changes in splice site proximity that have been shown to affect splice site selection (Reed and Maniatis 1986). In the case of the $\mathrm{E} 17$ deletion, the better match of the E16 $5^{\prime}$-splice site to the consensus sequence (E16: CUC/GUGAGU, E17: CGA/GUACGU/ may also be involved. Exchanging the $3^{\prime}$-splice site associated with E18 for a constitutively used site from the $\alpha$-globin gene might have been expected to greatly increase E18 inclusion. Instead, E18 utilization remained unchanged in undifferentiated cells and was rather depressed in differentiated cells although differentiation-dependent control was still observed. According to the criteria of Smith et al. (1989b), this substitution included the branchpoint and its associated polypyrimidine stretch. An AG dinucleotide is found 44 nucleotides upstream of the intron/exon border, thus restricting the location of the putative branchpoint to this segment. We do not know the mechanism by which the elements that constitute a functional 3 '-splice sitebranchpoint, polypyrimidine tract, and the splice site itself-might influence the level of E18 use. At least for the differentiation state-dependent regulation, the native sequences do not seem to play a fundamental role.

We have identified the $5^{\prime}$-splice site of the optional NCAM E18 as a pivotal element in the differentiationstate dependent control of its alternative splicing in N2a neuroblastoma cells. We are now in a position to search for the binding of specific factors, the expression or activity of which is altered during differentiation. Our system has the advantage that the splicing pathway can be modified in the same clonal cell line simply by changing culture conditions. In this way, effects on splicing per se can potentially be distinguished from effects on its regulation.

The shift in the mode of splicing of the NCAM gene that occurs during differentiation of $\mathrm{N} 2 \mathrm{a}$ cells reproduces what takes place during neural maturation in vivo. NCAM-180, the product of the mRNA, which includes E18, is essentially specific for postmitotic neurons (Persohn and Schachner 1987; Prieto et al. 1989). Its accumulation at sites of cell-cell contact in culture (Pollerberg et al. 1987) and at subsynaptic sites in vivo (Persohn et al. 1989) suggests that this NCAM isoform plays a role in stabilizing permanent contacts such as those constituted by synapses. The mechanisms governing the expression of the NCAM-180-specific mRNAs may therefore be part of a developmental program involved in regulating alternative splicing not only in the NCAM gene but also in other genes expressed in differentiating neurons.

\section{Materials and methods}

\section{Constructions}

The expression vector pUHD10-1 (Deuschle et al. 1989) containing the CMV promoter and a SV40-derived poly(A) addition signal was used as vector for all constructs. Partial NCAM cDNAs containing or lacking E18 are identical with the EcoRIAsp718 fragments of clone N22 (Barthels et al. 1988) or DW2 
(Santoni et al. 1987), respectively, which were inserted into the vector by directional cloning.

pNC16-19 To obtain the basic minigene construct, the HpaI fragment of cosmid 4.1 (Barbas et al. 1988) was inserted into the SmaI site of the pUHD 10-1 polylinker.

pNC16-18 The resulting contruct was cut with BamHI to remove the NCAM sequences $3^{\prime}$ of the BamHI site in E17, which were subsequently replaced by the insertion of pB22 (Barbas et al. 1988).

pNC16-18/G3 The NarI-ApaI fragment of pSVed $\alpha 2$ (Higgs et al. 1983) was inserted into the SmaI site of pGEM7Z (Promega Biotec), excised as a BamHI-EcoRI fragment, and inserted blunt-ended into the XbaI-site of pNC16-18.

$p N C 16 / 18 / 19$ The $A c c I-B g l$ II fragment containing E17 was excised from pNC16-18. An NcoI fragment containing the desired deletion was then exchanged for the corresponding fragment in pNC16-19.

Internal deletions Internal deletions in E18 were obtained by insertion of a SalI linker into the central StuI site and subsequent digestion of the Sall-linearized plasmid with Bal31. To obtain deletion $\Delta \mathrm{il} 17$ the BglII-SphI fragment of IVS17 was removed. The large deletion within IVS18 $(\Delta \mathrm{i} 18)$ involved linearization of $\mathrm{pNCl}$-19 by Tthl11I restriction enzyme and subsequent digestion with Bal31.

$p N C 16 / 17 / 18^{G 2 a} / 19$ First, the SmaI-PmlI fragment of pSVed 2 containing the 3 '-splice site of $\alpha$-globin E2 was inserted into the $\mathrm{Ncol}$ site of pGEM5Z (Promega Biotec), choosing the orientation yielding sense transcripts from the SP6 promoter. A SalI linker was inserted into the StuI site of E18 in pNC16-19, and the resulting SphI-SalI fragment containing the E18 $3^{\prime}$-splice site cloned downstream from the $\alpha$-globin fragment (in the same orientation) between the EcoRV and SalI sites of the pGEM5Z polylinker. The desired $\alpha$-globin-NCAM fusion was created by deleting excess sequences via PCR amplification of the whole plasmid linearized with SstII. The amplified plasmid was recircularized after phosphorylation. Subsequently, the original SphI-SalI fragment was replaced with the corresponding modified fragment excised from the amplified plasmid.

$p N C 16 / 17 / 18^{G 2 d} / 19$ The SphI-ApaI fragment containing E18 was cloned between the respective sites in pGEM5Z. By PCR amplification of the whole plasmid, a small deletion encompassing the 5 '-splice site of E18 and a unique ClaI site /resulting from $\mathrm{T} \rightarrow \mathrm{A}$ mutagenesis within the intron, 79 nucleotides downstream from the exon/intron boundary/ were first created. A double-stranded synthetic 23-mer oligodeoxynucleotide including the $\alpha$-globin E2 5 '-splice site was then inserted between the PstI site in E18 and the ClaI site. Subsequent cloning steps were carried out to establish the modification in pNC16-19. Missing intron sequences were finally added with a fragment generated by PCR.

pNC16/17/18 G2N18d $/ 19$ The PstI-ClaI fragment of pNC16/17/ $18^{\mathrm{G} 2 \mathrm{~d}} / 19$ containing the $\alpha$-globin sequences was replaced by a double-stranded oligodeoxynucleotide containing the desired sequence.

$\alpha$-Globin minigenes $\alpha$-Globin sequences inserted into pUHD10-1 start with the NcoI site in El and terminate with the ApaLI site in E3. Constructs containing E16 and E17 of the NCAM gene resulted from exchange of the NcoI-SmaI fragment containing $\mathrm{E} 1$ of the $\alpha$-globin gene for the $\mathrm{HpaI}-\mathrm{Bg} / \mathrm{II}$ fragment of pNC16-19. Removal of the $\alpha$-globin E2 5'-splice site in constructs 2 and 4 (Fig. 8) was achieved by replacing any sequence between the upstream $P m I$ and the downstream NarI site by a ClaI linker. The ClaI site was then used to insert a fragment containing the NCAM E18 $5^{\prime}$-splice site generated by PCR.

$p G 1 / 2^{N 18 d} / 3 \quad$ Mutagenesis of the $\alpha$-globin E2 $5^{\prime}$-splice site to the E18 5'-splice site was accomplished by PCR amplification of the whole plasmid with a mutant primer.

\section{Cell culture and transfections}

Cells were cultured in Dulbecco's modified Eagle medium (DMEM) containing 10\% fetal calf serum. One day before transfection, cells were harvested by a brief treatment with trypsin in PBS-EDTA and replated in $60-\mathrm{mm}$ dishes at a density of $2.2 \times 10^{5}$ cells per dish. Cells were transfected by calcium phosphate coprecipitation (Hirsch et al. 1990), generally with $1 \mu \mathrm{g}$ of the specific plasmid and $7 \mu \mathrm{g}$ of an unrelated plasmid, pTCF (Grosveld et al. 1982), per plate. The precipitate was removed after $20 \mathrm{hr}$, and the cells were harvested after another $24 \mathrm{hr}$. To induce differentiation, the transfected N2a cells were switched to $2 \%$ DMSO, $0.2 \%$ FCS in DMEM (Pollerberg et al. 1986) immediately after the removal of the precipitate and maintained under these conditions for 7 days before being harvested. Cells from two culture dishes were transfected, processed, and analyzed in parallel in each experiment, which was repeated at least once with a different batch of cells.

\section{RNA analysis}

Total RNA was isolated by guanidinium thiocyanate-phenolchloroform extraction (Chomczynski and Sacchi 1987). Northern blot analysis was performed exactly as described (Roubin et al. 1990). RNase protection experiments followed the protocol of Zinn et al. (1983), except that RNase treatment was performed at $20^{\circ} \mathrm{C}$. The DNA fragments used for synthesis of ${ }^{32} \mathrm{P}$ labeled antisense RNA were derived from the E18-containing NCAM cDNA clone N22 (Barthels et al. 1988) or from pSVed 2 (Higgs et al. 1983), respectively. The 454-nucleotide StuI-BgII fragment of N22 starting in E16 and terminating in E18 was cloned blunt-ended into the SmaI site of pGEM7Z (Promega Biotec) to allow for synthesis of the $5^{\prime}$ probe from the T7 promoter after linearization of the template plasmid with ClaI. Because the StuI site is located 118 nucleotides upstream of the HpaI site in E16, which constitutes the 5' end of all NCAM minigenes, this probe enabled us to distinguish between endogenous and exogenous NCAM transcripts (see Fig. 2). Synthesis of the 3' probe by T3 polymerase was from a PstI-KpnI fragment of N22 directionally cloned into the Bluescript KS vector (Stratagene). The template plasmid was linearized with BamHI. RNase protection analysis of exogenous $\alpha$-globin transcripts was performed with the NarI-ApaI fragment of the $\alpha 2$-globin gene inserted blunt-ended into the SmaI site of pGEM7Z. The 
probe, which comprises 179 nucleotides of exon 3 and $148 \mathrm{nu}$ cleotides of IVS2, was generated from the T7 promoter after linearization of the template plasmid with ClaI. Autoradiographic signals of protected fragments separated on $6 \%$ denaturing polyacrylamide gels were quantified with a GS300 scanning densitometer (Hoefer Scientific Instruments) on exposures within the linear range of the film. All values were corrected for incorporation of $\left[{ }^{32} \mathrm{P}\right] \mathrm{UTP}$, used as radioactive label, into the protected fragments of different size and base composition.

Primer extension of $\alpha$-globin transcripts, coupled with amplification by PCR, was performed with a single buffer system as suggested previously (Sherman et al. 1989), but employing three different primers. Each reaction contained $\sim 10 \mu \mathrm{g}$ of total RNA and $10 \mathrm{ng}$ of reverse transcription primer $5^{\prime}$-CACGGCAGGGGTGAACTCGGCGGG-3' complementary to nucleotides 4167 of E3. Reverse transcription was performed for $30 \mathrm{~min}$ at $42^{\circ} \mathrm{C}$. For PCR amplification of the cDNA, $600 \mathrm{ng}$ each of sense and antisense primers was used. Sense primers comprised nucleotides 45-63 of E1 (5'-TAAGGTCGGCGCGCACGCT-3') or nucleotides 179-198 of NCAM E16 (5'-AGACATGGAGGAGGGCAAGG-3'), respectively. Antisense primer 5'-GGAATTCGGTGACGGACGA-3' complementary to nucleotides 3-20 of E3 was used throughout. PCR cycles (15-20) were applied with the following steps: $1 \mathrm{~min}$ at $94^{\circ} \mathrm{C}, 30 \mathrm{sec}$ at $55^{\circ} \mathrm{C}$, and $2 \min$ at $72^{\circ} \mathrm{C}$.

\section{Acknowledgments}

We thank Ulrich Deuschle for the CMV expression vector pUHD10-1, Nick Proudfoot for pSVedo2, and Wolfgang Wille and Dagmar Barthels for DW2 and N22. We are grateful to Daniel Campèse for oligodeoxynucleotide synthesis. We also thank Jean-François Brunet, Bertrand Jordan, and Didier Marguet for critical reading of the manuscript, and Corinne Bézier La Fosse for the artwork. In the course of this work, R.T. was consecutively supported by fellowships from the Fondation pour la Recherche Médicale, the Institut National de la Santé et de la Recherche Médicale (INSERM), and the Deutsche Forschungsgemeinschaft. The work was supported by institutional grants from the Centre National de la Recherche Scientifique and INSERM and by a specific grant from the Association pour la Recherche contre le Cancer.

The publication costs of this article were defrayed in part by payment of page charges. This article must therefore be hereby marked "advertisement" in accordance with 18 USC section 1734 solely to indicate this fact.

\section{References}

Amrein, H., M. Gorman, and R. Nöthiger. 1988. The sex-determining gene tra- 2 of Drosophila encodes a putative RNA binding protein. Cell 55: 1025-1035.

Bandziulis, R.J., M.S. Swanson, and G. Dreyfuss. 1989. RNAbinding proteins as developmental regulators. Genes \& Dev. 3: $431-437$.

Barbas, J.A, J.C. Chaix, M. Steinmetz, and C. Goridis. 1988. Differential splicing and alternative polyadenylation generates distinct NCAM transcripts and proteins in the mouse. EMBO I. 7: 625-632.

Barthels, D., G. Vopper, and W. Wille. 1988. NCAM-180, the large isoform of the neural cell adhesion molecule of the mouse, is encoded by an alternatively spliced transcript. $\mathrm{Nu}$ cleic Acids Res. 16: 4217-4225.
Chomczynski, P. and N. Sacchi. 1987. Single-step method of RNA isolation by acid guanidinium thiocyanate-phenolchloroform extraction. Anal. Biochem. 162: 156-159.

Cunningham, B.A, J.J. Hemperly, B.A. Murray, E.A Prediger, R. Brackenbury, and G.M. Edelman. 1987. Neural cell adhesion molecule: Structure, immunoglobulin-like domains, cell surface modulation and alternative RNA splicing. Science 236: 799-806.

Deuschle, U., R. Pepperkok, F. Wang, T.J. Giordano, W.T. McAllister, W. Ansorge, and H. Bujard. 1989. Regulated expression of foreign genes in mammalian cells under the control of coliphage T3 RNA polymerase and Lac repressor. Proc. Natl. Acad. Sci. 86: 5400-5404.

Dickson, G., D. Peck, S.E. Moore, C.H. Barton, and F. Walsh. 1990. Enhanced myogenesis in NCAM-transfected mouse myoblasts. Nature 344: 348-351.

Edelman, G.M. 1988. Morphoregulatory molecules. Biochemistry 27: 3533-3543.

Emeson, R.B., F. Hedjron, J.M. Yeakley, J.W. Guise, and M.G. Rosenfeld. 1989. Alternative production of calcitonin and CGRP mRNA is regulated at the calcitonin-specific splice acceptor. Nature 341: 76-80.

Eperon, L.P., J.P. Estibeiro, and I.C. Eperon. 1986. The role of nucleotide sequences in splice site selection in eukaryotic pre-messenger RNA. Nature 324: 280-282.

Eperon, L.P., I.R. Graham, A.D. Griffiths, and I.C. Eperon. 1988. Effects of RNA secondary structure on alternative splicing of pre-mRNA: Is folding limited to a region behind the transcribing RNA polymerase? Cell 54: 393-401.

Fin, X.-Y. and J.L. Manley. 1987. Factors influencing alternative splice site utilization in vivo. Mol. Cell. Biol. 7: 738-748.

$\mathrm{Fu}, \mathrm{X} . \mathrm{-Y}$., H. Ge, and J.L. Manley. 1988. The role of the polypyrimidine stretch at the SV40 early pre-mRNA 3 'splice site in alternative splicing. EMBO 1. 7: 809-817.

Gallego, M.E. and B. Nadal-Ginard. 1990. Myosin light-chain 1/3 gene alternative splicing: Cis regulation is based upon hierarchical compatibility between splice sites. Mol. Cell. Biol. 10: 2133-2144.

Gattoni, R., P. Schmitt, and J. Stevenin. 1988. In vitro splicing of adenovirus E1A transcripts: Characterization of novel reactions and of multiple branch points abnormally far from the 3'-splice site. Nucleic Acids Res. 16: 2389-2409.

Ge, H. and J.L. Manley. 1990. A protein factor, ASF, controls cell-specific alternative splicing of SV40 early pre-mRNA in vitro. Cell 62: 25-34.

Goridis, G., M.-J. Santoni, M.-R. Hirsch, J. Barbas, D. Barthels, and W. Wille. 1989. Generation of diversity in the NCAM adhesion protein of rodents. In Cell to cell signals in mammalian development NATO ASI Series (ed. S.W. De Laat, J.G. Bluemink, and C.L. Mummery|, Vol. H26, pp. 129-143. Springer, Berlin/Heidelberg.

Goux-Pelletan, M., D. Libri, Y. d'Anbenton-Carafa, M. Fiszman, E. Brody, and J. Marie. 1990. In vitro splicing of mutually exclusive exons from the chicken beta-tropomyosin gene: Role of the branch point location and very long pyrimidine stretch. EMBO I. 9: 241-249.

Grosveld, F.G., T. Lund, E.J. Murray, A.L. Mellor, H.H.M. Dahl, and R.A Flavell. 1982. The construction of cosmid libraries which can be used to transform eukaryotic cells. Nucleic Acids Res. 10: 6715-6732.

Helfman, D.M. and W.M. Ricci. 1989. Branch point selection in alternative splicing of tropomyosin pre-mRNAs. Nucleic Acids Res. 17: 5633-5650.

Helfman, D.M., R.F. Roscigno, G.J. Mulligan, L.A. Finn, and K.S. Weber. 1990. Identification of two distinct intron elements involved in alternative splicing of $\beta$-tropomyosin pre- 
mRNA. Genes \& Dev. 4: 98-110.

Higgs, D.R., S.E.Y. Goodbourn, J. Lamb, J.B. Clegg, D.J. Weatherall, and N.J. Proudfoot. 1983. $\alpha$-Thalassaemia caused by a polyadenylation signal mutation. Nature 306: 398-400.

Hirsch, M.-R., L. Gaugler, H. Deagostini-Bazin, L. Bally-Cuif, and C. Goridis. 1990. Identification of positive and negative regulatory elements governing expression of the NCAM gene. Mol. Cell. Biol. 10: 1959-1962.

Inoue, K., K. Hoshijima, H. Sakamoto, and Y. Shimura. 1990. Binding of the Drosophila Sex-Lethal gene product to the alternative splice site of transformer primary transcript. $\mathrm{Na}$ ture 344: 461-463.

Krainer, A.R., G.C. Conway, and D. Kozak. 1990a. The essential pre-mRNA splicing factor SF2 influences 5 '-splice site selection by activating proximal sites. Cell 62: $35-42$.

- 1990b. Purification and characterization of pre-mRNA splicing factor SF2 from HeLa cells. Genes \& Dev. 4: 11581171.

Kuo, H.-C., F.H. Nasim, and P.J. Grabowski. 1991. Control of alternative splicing by the differential binding of U1 small nuclear ribonucleoprotein particle. Science 251: 1045-1050.

Landmesser, L., L. Dahm, K. Schultz, and U. Rutishauser. 1988. Distinct roles for adhesion molecules during innervation of embryonic chick muscle. Dev. Biol. 130: 645- 670.

Lear, A.L., L.P. Eperon, I.M. Wheatley, and I.C. Eperon. 1990. Hierarchy for $5^{\prime}$-splice site preference determined in vivo. $J$. Mol. Biol. 211: 103-115.

Libri, D., M. Goux-Pelletan, E. Brody, and M.Y. Fiszman. 1990. Exon as well as intron sequences are cis-regulating elements for the mutually exclusive alternative splicing of the $\beta$ tropomyosin gene. Mol. Cell. Biol. 10: 5036-5046.

Mardon, H.J., G. Sebastio, and F. Baralle. 1987. A role for exon sequences in alternative splicing of the human fibronectin gene. Nucleic Acids Res. 15: 7725-7733.

Mattaj, I.W. and J. Hamm. 1989. Regulated splicing in early development and stage-specific U snRNPs. Development 105: 183-189.

Nagoshi, R.N. and B.S. Baker. 1990. Regulation of sex-specific RNA splicing of the Drosophila doublesex gene: Cis-acting mutations in exon sequences alter sex-specific RNA splicing patterns. Genes \& Dev. 4: 89-97.

Nasim, F.H., P.A. Spears, H.M. Hoffmann, H. Kuo, and P.J. Grabowski. 1990. A sequential splicing mechanism promotes selection of an optional exon by repositioning a downstream 5 -splice site in preprotachykinin pre-mRNA. Genes \& Dev. 4: 1172-1184.

Noble, J.C.S., C. Prives, and J.L. Manley. 1988. Alternative splicing of SV40 early pre-mRNA is determined by branch site selection. Genes \& Dev. 2: 1460-1475.

Owens, G.C., G.M. Edelman, and B.A. Cunningham. 1987. Organization of the neural cell adhesion molecule (N-CAM) gene: Alternative exon usage as the basis for different membrane associated domains. Proc. Natl. Acad. Sci. 84: 294298.

Padgett, R.A, P.J. Grabowski, M. Konarska, S. Seiler, and P.A Sharp. 1986. Splicing of messenger RNA precursors. Annu. Rev. Biochem. 55: 1119-1150.

Persohn, E. and M. Schachner. 1987. Immunoelectron-microscopic localization of the neural cell adhesion molecules $\mathrm{Ll}$ and N-CAM during postnatal development of the mouse cerebellum. I. Cell Biol. 105: 569-576.

Persohn, E., E. Pollerberg, and M. Schachner. 1989. Immunoelectron-microscopic localization of the $180 \mathrm{kD}$ component of the neural cell adhesion molecule N-CAM in postsynaptic membranes. I. Comp. Neurol. 288: 92-100.

Pollerberg, E., M. Schachner, and J. Davoust. 1986. Differentia- tion-state dependent-surface mobilities of two forms of the neural cell adhesion molecule. Nature 324: 462-465.

Pollerberg, E., K. Burridge, K. Krebs, S. Goodman, and M. Schachner. 1987. The $180 \mathrm{kD}$ component of the neural cell adhesion molecule N-CAM is involved in cell-cell contacts and cytoskeleton-membrane interactions. Cell Tissue Res. 250: 227-236.

Prieto, A.L., K.L. Crossin, B. Cunningham, and G.M. Edelman. 1989. Localization of mRNA for neural cell adhesion molecule (N-CAM) polypeptides in neural and nonneural tissues by in situ hybridization. Proc. Natl. Acad. Sci. 86: 95799583.

Reed, R. and T. Maniatis. 1986. A role for exon sequences and splice-site proximity in splice-site selection. Cell 46: 681690.

-1988. The role of the mammalian branchpoint sequence in pre-mRNA splicing. Genes \& Dev. 2: 1268-1276.

Roubin, R., H. Deagostini-Bazin, M.-R. Hirsch, and C. Goridis. 1990. Modulation of NCAM expression by transforming growth factor-beta, serum, and autocrine factors. $I$. Cell. Biol. 111: 673-684.

Rutishauser, J. and T.M. Jessell. 1988. Cell adhesion molecules in vertebrate neural development. Physiol. Rev. 68: 819857.

Santoni, M.-I., D. Barthels, J.A Barbas, M.-R. Hirsch, M. Steinmetz, C. Goridis, and W. Wille. 1987. Analysis of cDNA clones that code for the transmembrane forms of the mouse neural cell adhesion molecule (NCAM) and are generated by alternative RNA splicing. Nucleic Acids Res. 15: 86218641 .

Santoni, M.-J., D. Barthels, G. Vopper, A. Boned, C. Goridis, and W. Wille. 1989. Differential exon usage involving an unusual splicing mechanism generates at least 8 types of NCAM cDNA in mouse brain. EMBO J. 8: 385-392.

Sherman, D.R., J. Geliebter, and A.M. Cross. 1989. Rapid and simple amplification of RNA sequence by the polymerase chain reaction. Trends Genet. 5: 137.

Siebel, C.W. and D.C. Rio. 1990. Regulated splicing of the Drosophila $\mathrm{P}$ transposablc element third intron in vitro: Somatic repression. Science 248: 1200-1208.

Silver, J. and U. Rutishauser. 1984. Guidance of optic axons in vivo by preformed adhesive pathways and neuroepithelial endfeet. Dev. Biol. 106: 486-499.

Smith, C.W.J. and B. Nadal-Ginard. 1989. Mutually exclusive splicing of alpha tropomyosin exons enforced by an unusual lariat branch point location: Implications for constitutive splicing. Cell 56: 749-758.

Smith, C.W.J., J.G. Patton, and B. Nadal-Ginard. 1989a. Alternative splicing in the control of gene expression. Annu. Rev. Genet. 23: 527-577.

Smith, C.W.J., E.B. Porro, J.G. Patton, and B. Nadal-Ginard. $1989 \mathrm{~b}$. Scanning from an independently specified branch point defines the $3^{\prime}$-splice site of mammalian introns. $\mathrm{Na}$ ture 342: 243-247.

Solnick, D. 1985. Alternative splicing caused by RNA secondary structure. Cell 43: 667-676.

Sosnowski, B.A, J.M. Belote, and M. McKeown. 1989. Sex-specific alternative splicing of RNA from the transformer gene results from sequence-dependent splice site blockage. Cell 58: 449-459.

Streuli, M. and H. Saito. 1989. Regulation of tissue-specific alternative splicing: Exon-specific cis-elements govern the splicing of leukocyte common antigene pre-mRNA EMBO $J$. 3: 787-796.

Tsai, A.Y.M., M. Streuli, and H. Saito. 1989. Integrity of the exon 6 sequence is essential for tissue-specific alternative 
splicing of human leukocyte common antigen pre-mRNA. Mol. Cell. Biol. 9: 4550-4555.

Zachar, A., T.B. Chou, and P. Bingham. 1987. Evidence that a regulatory gene autoregulates splicing of its transcript. $E M B O$ I. 6: 4105-4111.

Zhuang, Z., H. Leung, and A. Weiner. 1987. The natural 5'splice site of simian virus 40 large $T$ antigen can be improved by increasing the base complementarity to Ul RNA. Mol. Cell. Biol. 7: 3018-3020.

Zinn, K., D. DiMaio, and T. Maniatis. 1983. Identification of two distinct regulatory regions adjacent to the human $\beta$-interferon gene. Cell 34: 865-879. 


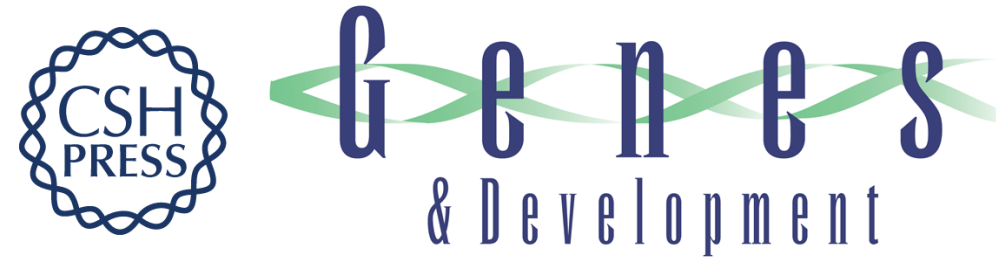

\section{Alternative splicing in the neural cell adhesion molecule pre-mRNA: regulation of exon 18 skipping depends on the 5 '-splice site.}

$\mathrm{R}$ Tacke and $\mathrm{C}$ Goridis

Genes Dev. 1991, 5:

Access the most recent version at doi:10.1101/gad.5.8.1416

References

This article cites 61 articles, 21 of which can be accessed free at:

http://genesdev.cshlp.org/content/5/8/1416.full.html\#ref-list-1

License

Email Alerting

Receive free email alerts when new articles cite this article - sign up in the box at the top

Service right corner of the article or click here.

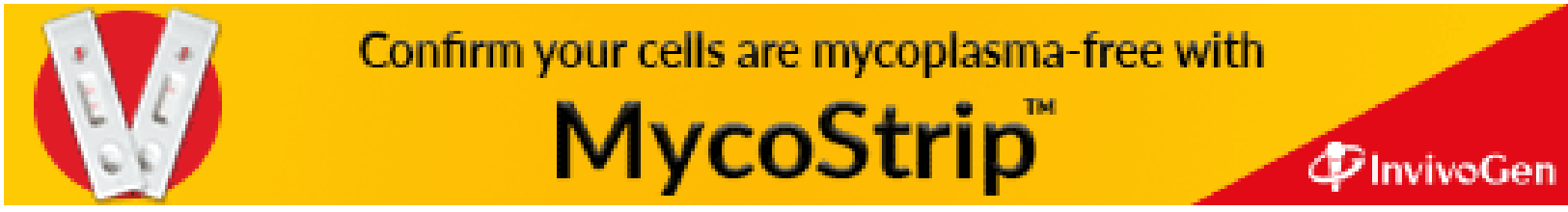

